\title{
Economía del espacio carcelario amplio: una cárcel limeña en el centro de múltiples operaciones informales
}

Économie de l'espace carcéral élargi : une prison liménienne au centre de multiples opérations informelles

Economy of the expanded prison space: a prison in Lima at the heart of multiple informal operations

\section{Chloé Constant}

\section{OpenEdition}

Journals

Edición electrónica

URL: http://journals.openedition.org/bifea/4367

DOI: 10.4000/bifea.4367

ISSN: 2076-5827

Editor

Institut Français d'Études Andines

Edición impresa

Fecha de publicación: 1 mayo 2014

Paginación: 93-110

ISSN: 0303-7495

Referencia electrónica

Chloé Constant, «Economía del espacio carcelario amplio: una cárcel limeña en el centro de múltiples operaciones informales », Bulletin de l'Institut français d'études andines [En línea], 43 (1) | 2014 ,

Publicado el 08 mayo 2014, consultado el 05 noviembre 2020. URL : http://journals.openedition.org/ bifea/4367 ; DOI : https://doi.org/10.4000/bifea.4367

\section{cc)}

Les contenus du Bulletin de l'Institut français d'études andines sont mis à disposition selon les termes de la licence Creative Commons Attribution - Pas d'Utilisation Commerciale - Pas de Modification 4.0 International. 


\title{
Economía del espacio carcelario amplio: una cárcel limeña en el centro de múltiples operaciones informales
}

\author{
Chloé Constant*
}

\begin{abstract}
Resumen
El presente artículo se basa en un trabajo de campo realizado adentro y en los alrededores de la cárcel limeña que acoge al mayor número de mujeres privadas de libertad en el Perú. Propone analizar los mecanismos que rigen un conjunto de operaciones económicas que no están limitadas al espacio carcelario sino que extienden su influencia a un área geográfica vinculada al establecimiento penitenciario. Entrevistas a profundidad permiten conocer la variedad de actores presentes en el espacio carcelario amplio, entender sus papeles y funciones en la red económica que se ha ido tejiendo a lo largo del tiempo entre el interior y el exterior de la cárcel. La comprensión de la complejidad de este universo se basa en los conceptos de desviación y cultura de la transgresión para dar a conocer una realidad poco explorada hasta hoy.
\end{abstract}

Palabras clave: cárcel, mujeres, informalidad, transgresión, desviación, Perú, Lima

\section{Économie de l'espace carcéral élargi : une prison liménienne au centre de multiples opérations informelles}

\section{Résumé}

Le présent article s'appuie sur un travail de terrain réalisé à l'intérieur et aux alentours de la prison liménienne qui accueille le plus grand nombre de femmes privées de liberté au Pérou. II propose d'analyser les mécanismes qui régissent un ensemble d'opérations économiques qui ne sont pas limitées à l'espace carcéral mais qui étendent leur rayonnement à une aire géographique liée à l'établissement pénitentiaire. Des entretiens approfondis permettent de connaître la variété des acteurs 
présents dans l'espace carcéral élargi, de comprendre leurs rôles et leurs fonctions dans le réseau économique qui s'est tissé au fil du temps entre l'intérieur et l'extérieur de la prison. La compréhension de la complexité de cet univers repose sur les concepts de déviance et de culture de la transgression pour donner à connaître une réalité encore jamais explorée jusqu'à aujourd'hui.

Mots-clés : prison, femmes, informalité, transgression, déviance, Pérou, Lima

\title{
Economy of the expanded prison space: a prison in Lima at the heart of multiple informal operations
}

\begin{abstract}
This paper is based on a fieldwork realized inside and in the neighbourhood of the prison that shelters the highest number of female inmates in Peru. Its purpose is to analyse the mechanisms that govern a set of economic operations, which are not restricted to the prison space, but have an influence on a geographic area that is linked to the prison building. In-depth interviews make it posible to identify a variety of actors that are present in the expanded prison space and understand their roles and functions inside the economic network that have been formed over time that link the areas inside and outside the prison. Understanding the complexity of this universe is made possible through the use of two concepts, deviance and transgression culture, and application of these concepts reveal a previously unexplored reality.
\end{abstract}

Keywords: prison, women, informality, transgression, deviance, Peru, Lima

\section{LA CULTURA DE LA INFORMALIDAD COMO HERRAMIENTA DE ESTUDIO DEL INTERFACE ENTRE EL INTERIOR Y EL EXTERIOR DE LA CÁRCEL}

\section{1. La informalidad y la cultura de transgresión}

En su obra titulada El Perú fracturado. Formalidad, informalidad y economía delictiva, Francisco Durand distingue tres tipos de economía que se desarrollan en la sociedad peruana: la economía formal, la economía informal y la economía delictiva (Durand, 2007). El funcionamiento paralelo de estas tres economías encontraría su origen en cuatro factores. Primero, Durand subraya que el crecimiento demográfico, si no constituye una causa en sí, representa «un elemento que acelera la acción de los factores causales» (Durand, 2007: 105). Efectivamente, el fuerte crecimiento demográfico y la migración rural masiva que marcaron la segunda mitad del siglo XX influenciaron de forma decisiva el mercado laboral cuya faceta formal no pudo absorber la creciente mano de obra, la que se orientó entonces hacia el mercado laboral informal, y a veces hacia la economía delictiva. Así, Durand sostiene que las nuevas generaciones «se socializan en un contexto de cultura de transgresión» (Durand, 2007: 106). De los cuatro factores que el autor distingue como los que originaron el crecimiento exponencial de la informalidad, se encuentra en primer lugar la crisis causada por el populismo que provocó un deterioro institucional, 
tanto del Estado como de las empresas y de la sociedad civil, en un contexto de estancamiento del mercado laboral formal, donde la informalidad apareció como una alternativa laboral viable. El segundo factor radica en el fracaso de los modelos de modernización aplicados sucesivamente desde los años 1960, y que nunca llevaron a ninguna creación masiva de empleos. El tercero radica en un contexto globalizado donde existe para las grandes empresas mano de obra más barata que en el Perú, hecho que se observa paralelamente con un régimen de derechos de propiedad y marcas, de los cuales provienen productos caros inasequibles para los consumidores más pobres. Este régimen impone un patrón de consumo al que no pueden acceder importantes categorías de la población, y así fomenta un mercado de imitaciones y contrabando. El último factor radica en el mal gobierno de un Estado con instituciones débiles que a duras penas intenta contener las prácticas informales y delictivas, y no emprende reformas por intereses vinculados a la corrupción, y por temor a los movimientos sociales. Durand concluye que existe un desarrollo paralelo de las tres formas de economía, formal, informal y delictiva, las que participan de forma generalizada a la cultura de la transgresión (Durand, 2007: 105-118).

Los análisis de Durand constituyen una fuente única que permite la comprensión de la amplitud del fenómeno de la informalidad en el Perú, más allá de otros estudios restringidos a algunos sectores, a determinadas épocas o áreas geográficas (Betalleluz, 2006; Canaza Paredes, 2006; Gonzáles, 2001; Grompone, 2005). Este artículo propone analizar cómo se traduce la cultura de la transgresión y de la informalidad en el espacio carcelario amplio del establecimiento penitenciario de mujeres de Chorrillos¹, ubicado en Lima, a través del estudio de los mecanismos y de los actores. Para ello, me centraré en un elemento que se encuentra en el corazón del cotidiano carcelario: el dinero. El dinero no solamente es central en la vida cotidiana de las internas: la proyección de su influencia sobrepasa los límites físicos de la cárcel. Por esto, referirse a un espacio carcelario amplio permite poner énfasis en que algunos intercambios económicos no se circunscriben al interior de la cárcel, sino que la existencia del establecimiento penal y su enmarcación dentro de la ciudad originan transacciones numerosas y de formas variadas que se realizan en la periferia del espacio carcelario, y permiten la supervivencia de un gran número de personas. En efecto, si las internas generan sus propios ingresos y tienen que encontrar cómo ganar el dinero suficiente para sobrevivir durante su estadía en la cárcel, los distintos actores que giran adentro y alrededor del espacio carcelario son numerosos, y cada uno desempeña un papel especial e imprescindible para mantener el sistema económico que se ha ido desarrollando a lo largo del tiempo. Los análisis que se presentan aquí permiten entender la complejidad de las interacciones económicas y de los intereses que vinculan el interior y las afueras de la cárcel. 


\section{2. Estudiar el interface entre adentro y afuera}

Estudiar la cárcel lleva a pensar y considerar un universo conformado no solamente por los internos y el conjunto del personal penitenciario, sino también por una variedad de actores vinculados directa o indirectamente a estos dos primeros grupos. Así como lo subrayó la antropóloga Manuela da Cunha, intentar entender el encierro penal pasa necesariamente por una comprensión global que incluye el interior y el exterior de la cárcel:

Para entender las percepciones de los internos, sus experiencias e interacciones, en otros términos para entender el encarcelamiento, sin el cual los debates sobre la cárcel no tendrían sentido, es necesario cambiar el enfoque desde el mundo interior hacia un enfoque que contemple el interface entre el adentro y el afuera, para así poder captar las redes de sentido que vinculan constantemente estos dos mundos2 (Cunha, 2005).

Para entender el universo de la cárcel de mujeres de Chorrillos en su conjunto, definiré quiénes son los actores satélites y analizaré sus papeles y estrategias, para entender cómo tejen sus redes. Para esta parte del estudio, los días de visita representaron una fuente especialmente rica de informaciones y observaciones. Paralelamente a las internas y a los miembros del Instituto Nacional Penitenciario (INPE) que ejercen dentro de la cárcel o en sus inmediaciones, los visitantes constituyen un grupo de actores centrales para estudiar las redes económicas informales que se crean alrededor del establecimiento penitenciario. Estos visitantes interactúan con un segundo grupo conformado por varios vendedores formales e informales, ubicados en los alrededores inmediatos de la cárcel. Para llevar a cabo el estudio de las interacciones entre estos grupos, y con la meta de comprender la complejidad de las relaciones que vinculan el interior y el exterior del establecimiento, realicé siete entrevistas semidirectivas con actores satélites. Defino a los actores satélites como una variedad de comerciantes, ambulantes o no, formales o informales, hombres y mujeres, que trabajan en las inmediaciones de la cárcel y que viven total o parcialmente de esta actividad. Muchos actores económicos ejercen así en la periferia de la cárcel y se pueden observar todos los días de la semana, pero la diversidad y la repartición de sus actividades los hacen particularmente visibles durante los días de visita. Pude recoger los testimonios de cuatro comerciantes que trabajan en conjunto en una tienda ubicada a unos pasos de la cárcel, de una vendedora ambulante que se encuentra frente a la fila de espera de los visitantes cada día de visita, de un tendero cuyo negocio está ubicado frente a la cárcel y finalmente de una ex interna que trabaja con las comerciantes mencionadas anteriormente. Todas las entrevistas se realizaron en el año 2009, al final de un día de visita, cuando se había reducido la actividad comercial, salvo en el caso del tendero cuyo negocio abre todos los días y que prefirió recibirme un día que no sea de visita, en 2011. Este trabajo de campo tenía como objetivo estudiar el sistema de visita como un «sistema organizado que despliega ciertas regularidades explicables, pero no siempre predictibles» (Daston, 1995). 
Construido a mediados del siglo XX, el establecimiento penitenciario de Chorrillos fue la primera cárcel peruana pensada para acoger exclusivamente a mujeres, y alberga hasta hoy a la mayor parte de la población carcelaria femenina del país, con 769 internas a finales del año 2012 (INPE, 2012). Las internas de esta cárcel se encuentran mayormente procesadas por delitos vinculados a las drogas (tráfico ilícito de drogas, microcomercialización o microproducción, promoción o favorecimiento al tráfico ilícito de drogas), y también por robo y hurto agravado. El 73,6 \% de ellas son jóvenes, con edades comprendidas entre 20 y 44 años (INPE, 2012), y el estudio de su trayectoria de vida demuestra que su acto delictivo se encuentra a menudo vinculado a la búsqueda de estrategias de supervivencia (Constant, 2013).

Los días de visita establecidos por la dirección del establecimiento son miércoles y domingo para mujeres, y sábado para hombres. El número de visitantes no está restringido, ni en absoluto, ni por cada interna, lo que explica, más allá del número de internas, la importancia del número de visitantes en cada uno de estos días, que puede superar las 300 personas.

\section{LOCALES COMERCIALES Y ACTORES QUE EJERCEN UNA ACTIVIDAD VINCULADA AL ESPACIO CARCELARIO AMPLIO}

\section{1. Los vendedores ambulantes itinerantes}

El vínculo que une a los vendedores ambulantes con la cárcel radica en cierta probabilidad de venta durante los días de visita. Los vendedores ambulantes son comprendidos aquí como vendedores itinerantes, tal como los ha definido De Soto, es decir personas que desarrollan una actividad comercial con pequeñas cantidades de productos que ofrecen deambulando en la calle, y operan a una escala bastante reducida (Soto, 1986: 67). Ofrecen a los visitantes caramelos, maní, frejol colado 3 y café, entre otros productos comestibles. Su presencia es más significativa por su regularidad que por su número, limitado a tres o cuatro. Su trabajo se basa exclusivamente en el intercambio económico con los visitantes, pero no se limita al sistema de venta. Una de las vendedoras, María Antonieta, cuenta que gana dinero guardando sitios desde muy temprano en la fila de espera para permitir a los visitantes que vienen desde bastante lejos que no entren muy tarde, ni que esperen mucho para entrar:

¿Vas a ir el 23? Porque va a estar así de gente (deja entender que va a ir mucha gente). Me han pedido que les guarde sitio en la cola para Navidad. Alquilo mis bancas, un sol ${ }^{4}$, pero tienen que venir temprano, a las 6 am

3 Postre tradicional de la costa sur del Perú.

4 Un «sol» designa el Nuevo Sol, la moneda peruana, que corresponde a un promedio de 0,30 dólares americanos. 
les digo tienen que venir, para cuando sellan porque sino se pierde el sitio. De ahí hago otra cola. Los días de fiesta, Navidad, día de la madre, son 20 soles. Los días normales son 5 soles. Ahora me han pedido para el 23 y para el 26, uno, dos el 23, dos el 26.

Esta estrategia recuerda la de la «guerra del centavo» donde los trabajadores no disponen de ninguna estabilidad laboral y dependen de los ingresos adquiridos en el día a día para su supervivencia (Bielich Salazar, 2009). Algunas fechas del calendario resultan entonces ser particularmente interesantes para estos actores que actúan individualmente y para quienes «las calles son la escuela donde aprenden qué productos son necesarios y qué valor tiene esta necesidad» (Soto, 1986: 68). En el caso de esta vendedora, a quien he visto todos los días que he ido de visita entre 2009 y 2012, su estrategia consiste no solamente en vender productos, sino también en brindar servicios que le fueron inspirados por su experiencia de venta en la calle, y particularmente frente a la cárcel.

\section{2. El comercio ambulante en un punto de venta fijo}

Otra categoría de vendedores que ejerce en las inmediaciones de la cárcel está conformada por actores que De Soto vincula al comercio ambulante, aunque los defina como comerciantes que dejaron de deambular e «identificaron un lugar donde se instalaron para desarrollar su actividad» (Soto, 1986: 68). Ubicado en la misma vereda que la cárcel de mujeres de Chorrillos, a unos pasos de la puerta de ingreso, un pequeño local comercial abre sus puertas tres días a la semana, los días de visita. Adentro y alrededor de este espacio trabaja un grupo de mujeres para quienes la ubicación geográfica del espacio comercial está estratégicamente vinculada a la proximidad de la cárcel. Estas mujeres solían ser vendedoras ambulantes itinerantes, y fueron amenazadas con ser desalojadas a raíz de los problemas de tránsito que ocasionaba su presencia en la vía. María Teresa es una de ellas y me contó cómo las autoridades municipales las presionaron para solucionar el problema:

¿Conoce la historia de esta tiendita?

Nosotros nunca hemos trabajado en tienda, hemos sido ambulantes. Esta tienda recién tiene tres años. Cómo no la voy a conocer así, trabajando acá tres años.

tres años... y ¿̇de quién surgió la idea de este negocio aquí?

Nosotros éramos ambulantes y el alcalde nos tuvo que reubicar, o sea que nosotros obligatoriamente tuvimos que arrendar tienda. Tú ves igual acá no hay nada (se refiere al hecho que el lugar no tiene ningún mueble).

Pero entonces ¿Uds tienen que alquilarlo?

Sí, este está alquilado.

¿Entre cuántos lo alquilan?

Tres.

Tres, y tú zeres una de ellas?

Sí. 


\section{Y ¿̇uánto está el alquiler?}

Ciento cincuenta.

¿Soles?

Dólares.

María Teresa y sus compañeras llegaron así a cierto grado de formalización pues alquilan un local de forma oficial. Sin embargo no emiten recibos de venta, por lo que no participan del sistema tributario, permaneciendo entonces vinculadas al sector informal.

El concepto de comercio ambulante desarrollado por De Soto resulta ser útil para analizar ciertas actividades que se desarrollan alrededor de la cárcel; sin embargo mis observaciones me llevaron a concluir cierta insuficiencia de esta base conceptual para el análisis del comercio ambulante en el espacio carcelario amplio. En efecto, a las tres inquilinas del local comercial se juntan entre cuatro y siete asistentes de venta que participan en la actividad comercial del lugar. Estas mujeres realizan el vínculo entre el local y la fila de espera, ofreciendo a los visitantes que se encuentran esperando los productos almacenados en el local. La actividad comercial ambulante sigue siendo en parte itinerante en la medida en que los productos de consumo y los servicios pueden ser adquiridos no solo en un punto de venta fijo, sino también directamente con las vendedoras ambulantes itinerantes que se encuentran en la vía pública. Norma es una de estas asistentas. Empleada por su tía, una de las tres inquilinas del local, Norma vincula el local con la fila de visitantes:

Cuando vengo lo primero que hago es ir a la cola, ofrecer los productos que entran al penal, y también lo que no entra se guarda. Y así estoy en este trajín, guardo, corro, lo que me piden...

Sí porque siempre te veo corriendo, siempre estás bien ocupada, ¿no?

Sí. Tengo que estar así, caminando para acá, corriendo para allá, lo que me piden, vendiendo y con la misma yendo así. Ya a las cuatro de la tarde ya no hay mucha cola me vengo acá a almorzar.

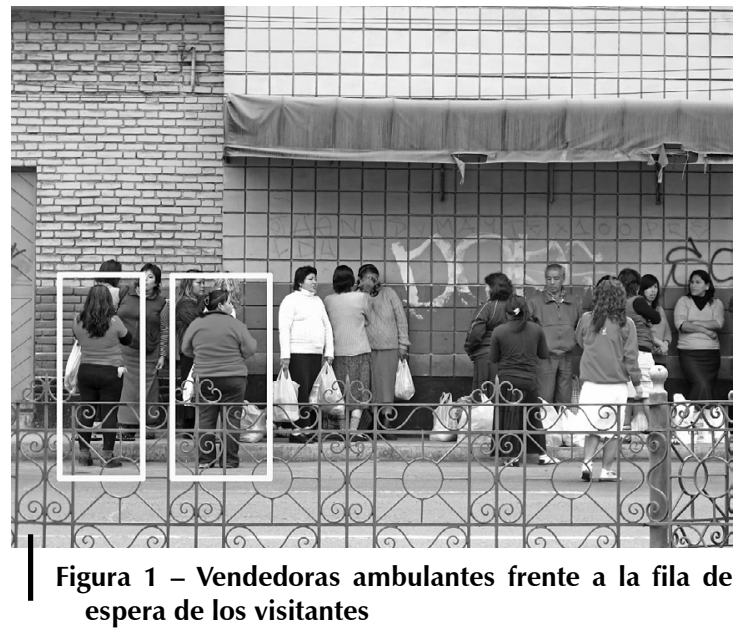

Fuente: archivos personales
En la figura uno, se puede apreciar a dos de las mujeres que trabajan entre el local y la fila de espera. Se puede notar que por más que su actividad esté vinculada a un local comercial, cuenta con los inconvenientes de la actividad ambulante vinculada a la vía pública, pues si la fila de espera se limita a la vereda, las vendedoras ambulantes se encuentran en una de las vías de tránsito de la avenida que bordea la cárcel. Como los muestra la figura 2, son también los transeúntes que deben de caminar por la calle para esquivar la fila. 


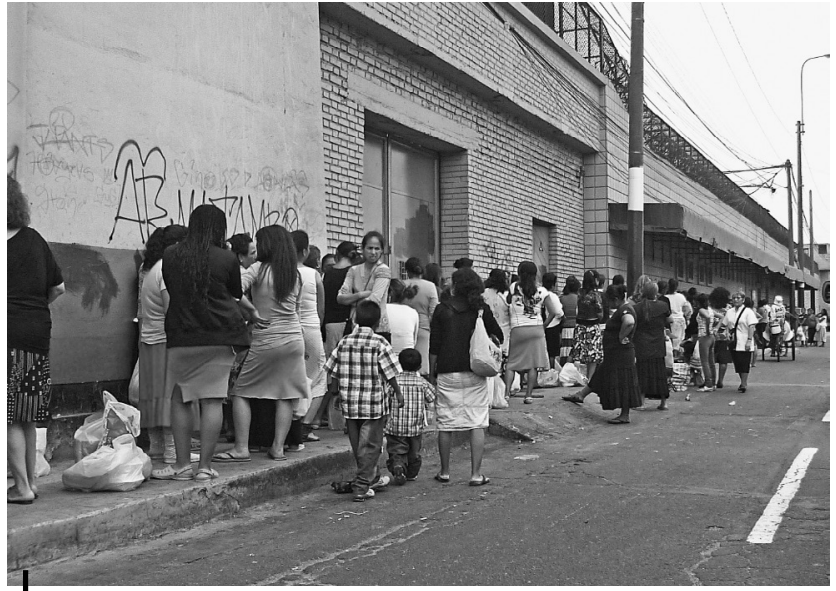

Figura 2 - Fila de espera un miércoles de visita frente a la cárcel de mujeres de Chorrillos

Fuente: archivos personales

\section{3. Los vendedores no ambulantes en un punto de venta fijo}

Varias tiendas están ubicadas en los alrededores de la cárcel y ofrecen productos todos los días de la semana y no solamente durante los días de visita, a contrario de la que se presentó anteriormente. La «Bodega Emmanuel» constituye un punto de venta y servicios clave dentro del universo carcelario amplio, como lo veremos más adelante. Emmanuel cuenta la historia del lugar y confirma que su actividad no solo está vinculada a la cárcel:

Esta tienda tiene... la tienda en sí tiene como 38 años. Antes de los 38, digamos desde el año 60, esta tienda no fue bodega sino que fue ferretería. Se vendían materiales para construcción. Y de 1965 para adelante, hasta ahora, fue bodega. (...) Normalmente abro a las siete de la mañana, de lunes a domingo, y a veces abro a las seis de la mañana cuando hay visita, que son los días miércoles, sábado y domingo.

Sin embargo, mostraré más adelante que la actividad comercial de esta bodega se encuentra altamente vinculada a la cercanía geográfica del establecimiento penitenciario.

\section{4. Cuando ex internas integran el comercio ambulante}

Entre los vendedores ambulantes que trabajan frente a la cárcel, otra categoría está conformada por ex internas. Estas mujeres no ejercen una actividad limitada a las afueras de la cárcel sino que ingresan en el establecimiento como visitantes. Cumplen doble papel: son visitantes y comerciantes. Los pequeños ingresos generados por las ventas que realizan frente a la cárcel durante los días de visita representan un apoyo económico sustancial para estas vendedoras improvisadas, oriundas de sectores sociales muy modestos. María B. es una de ellas. Durante una entrevista, su discurso traduce la búsqueda de una estrategia de supervivencia:

A veces sabe que es un gasto, el pasaje ${ }^{5}$ y todo lo demás, desde las 5:30 am hasta las 12 pm, para solventar mis gastos, mi pasaje, traigo cigarros, cositas como golosinas, para pasar adentro para poder vender y recuperar mi gasto de mi pasaje y algo así.

5 El término «pasaje» designa el precio del transporte, sea bus o taxi colectivo. 
María B. reside en el distrito de San Martin de Porres, bastante lejos de Chorrillos, pero visita a «una amistad» dos veces por semana. No solo debe asumir el costo de su viaje, sino también los que están vinculados a su alimentación durante el día. Sus ventas le permiten paliar los gastos que implican la visita y también conseguir un pequeño ingreso. Así como ella, varias ex internas ingresan a la cárcel como visitantes y viven parcialmente de las ventas que realizan allí:

No soy la única, somos varias, hay muchas que han salido de acá, que han estado adentro y se buscan la vida acá, porque ya no quieren delinquir, ya no quieren regresar, porque estar privada de tu libertad es lo peor que te pueda pasar, y no se le deseo a nadie. En cambio a veces se le pide ayuda a la gente de la cola, «mamita llévame mis cigarros», y te reciben, le das cola, y esa es la manera de cómo pueden pasar tus cigarros, tus cosas. Adentro lo recoges y lo vendes, pero no tan caro tampoco, a precio económico, porque adentro mismo están caras las cosas.

La estrategia de estas mujeres abarca entonces no solamente una dimensión económica, sino que también está considerada como una verdadera opción laboral, pues la venta ambulante representa una alternativa al ejercicio de actividades delictivas.

Las asistentas de venta como Norma también logran ingresar productos para venderlos adentro de la cárcel, generando de esta forma un ingreso que complementa su salario. ¿Cómo se comparte el mercado entre la multiplicidad de actores presentes? Según María B. todas son «amigas de venta» y ninguna competencia parece dividirlas. Al contrario, se arreglan entre ellas para hacer ingresar por medio de los visitantes todos sus productos, repartiéndoles entre esos, pues la administración restringe la cantidad de productos por cada visitante. Existe entonces cierto acuerdo tácito que vincula a las ex internas con las vendedoras itinerantes.

Siguiendo una lógica de pacto de respeto (Crozier \& Friedberg, 1996) del espacio, de las relaciones y del mercado, el conjunto del comercio se encuentra repartido entre las diversas actoras. Finalmente, el juego radica en la interacción de varios actores dentro de verdaderas redes humanas, materiales y económicas que vinculan al dentro con el afuera de la cárcel. Según las lógicas observadas y descritas por las distintas personas entrevistadas, nos encontramos frente a lo que conceptualizó Edward P. Thompson, analizado más adelante por D. Fassin: una economía moral. En efecto, se trata de un sistema donde se observa «el compromiso de los miembros los unos frente a los otros a través del intercambio de bienes y prestaciones de servicio dentro de la familia y dentro de redes de dependencia». Por otra parte, esta forma de economía «corresponde también a un sistema de normas y obligaciones (que) orientan los juicios y los actos, distingue lo que se hace de lo que no se hace» (Fassin, 2009: 1243). Efectivamente, presenciamos la creación de redes de dependencia conformadas por un lado por las internas que carecen de algunos productos básicos (Constant, 2011: 85-92), y por otro lado por un conjunto de comerciantes informales que dependen del espacio carcelario por su supervivencia. Las normas y obligaciones que surgen de esta situación de interdependencia representan la condición sine qua non para mantener los intereses de todas las partes. El desarrollo de este sistema peculiar se hace posible 
por un conjunto de condiciones estructurales: un Estado débil incapaz de proveer las necesidades de las internas, la enmarcación del establecimiento penitenciario dentro de la ciudad, y unos actores sociabilizados en una cultura de transgresión y búsqueda de estrategias de supervivencia.

\section{RENTABILIDAD DEL NEGOCIO CARCELARIO: ALQUILERES Y SERVICIOS MÚLTIPLES}

\section{1. El sistema de alquiler de ropa}

El alquiler de faldas, cuyo uso es obligatorio para las visitantes, constituye según María Teresa una práctica antigua:

La que trabajaba era mi mamá. Yo era chiquita, porque siempre ha existido eso pues, en todos los penales. En todos los penales existe el alquiler de faldas. Para las personas que traen pantalones.

El alquiler de ropa resulta ser muy común en la medida en que existe un verdadero uniforme del visitante que se aplica tanto a las mujeres como a los hombres. Los visitantes no pueden ingresar dentro de la cárcel con zapatos con cordones ni taco superior a tres centímetros, correa, capucha, sombrero, camiseta sin manga, chalinas ni lentes de sol. Las mujeres se ven obligadas a usar sostén y su ropa interior no debe ser roja. Los hombres no pueden ingresar en pantalones cortos. En tales condiciones, numerosos visitantes prefieren llegar hasta la cárcel en su vestimenta habitual y cambiarse o alquilar los elementos del uniforme que necesitan en las tiendas como la de María Teresa o de Emmanuel. La tienda de María Teresa y sus socias no solo ofrece alquilar de faldas, sino también camisetas, sostenes y sandalias. Ya que de los tres días semanales destinados a las visitas, dos son reservados para mujeres, el negocio de alquiler de faldas es el más rentable según María Teresa:

O sea que la falda ise alquila un sol?

Sí.

Y lo demás, ¿los polos?

Sandalias es un sol. El polo (camiseta), sale polo pero es muy poco la salida. Más se alquila faldas. Y por ejemplo ahorita la sandalias es poco.

Más es falda.

La primera vez que acudí sola a la visita, mientras estábamos en verano, tuve que recurrir a este servicio pues no pude ingresar con mi polo de espalda abierta y sin sostén. Estas prendas también se alquilan por un nuevo sol. La tienda de Emmanuel es otro lugar importante para alquilar ropa:

Los días de visita les guardamos las cosas a las familias, se cambian en la tienda, les alquilamos faldas, sandalias, les alquilamos el baño, les damos pues la mayoría de facilidades para que vayan a ver tranquilas a su familia. ¿Cuánto alquilas una falda?

Un sol.

¿Sandalias?

Igual. 
¿Para guardar paquetes?

Igual.

Un sol ¿todo eso un sol?

Un sol. Un sol dado.

(...)

Para los hombres también...

Zapatos, pantalones para los hombres...

¿Cuánto alquilas los zapatos?

Dos soles. iHasta mis zapatos! A veces me quedo en media por darle un par de zapatos a un compadre porque...

¿Y pantalón cuánto?

Dos soles igual.

Si el local donde trabaja María Teresa contrata exclusivamente a mujeres, alquila también mayormente a mujeres y los visitantes masculinos prefieren dirigirse a Emmanuel. La actividad comercial y los ingresos relativos a esta se encuentran entonces altamente condicionados por el sexo, y los discursos de los distintos vendedores traducen la integración de prácticas diferenciadas según el sexo. Por ejemplo Emmanuel no ofrece alquilar sostén. Paralelamente cuando le pregunto a María Teresa por qué son exclusivamente mujeres que trabajan con ella, me contesta:

Bueno porque, en mi caso, voy a hablar en mi caso, como es alquiler de falda no puede ser hombre.

Los hombres alquilan preferentemente a los hombres, y viceversa, a fortiori cuando el servicio está relacionado con vestimenta. En estos actores, la distinción entre lo masculino y lo femenino constituye definitivamente una norma social que determina los límites de un comportamiento aceptable (Héritier, 1996), que orienta e influye sobre sus opciones laborales.

\section{2. El sistema de consigna}

En la parte de la entrevista transcrita más arriba, Emmanuel menciona otro servicio que ofrece a los visitantes, servicio que también proponen María Teresa y sus socias: guardan las cosas de los familiares. Los visitantes no pueden ingresar a la cárcel con cartera, llaves, teléfonos celulares ni otros efectos personales. Antes de ingresar, se encuentran consecuentemente obligados a dejarlos en consigna, en una bolsa plástica cerrada marcada con su nombre, en uno de los locales comerciales. El costo de este servicio está comprendido entre 50 céntimos y dos nuevos soles, según el tamaño del paquete. Las reglas establecidas por el establecimiento en materia de visita implica entonces una serie de gastos para los visitantes, que se añaden a los que implican el viaje y las compras destinadas a las internas. Si bien es ciertamente posible no tener que alquilar ropa, las llaves son un objeto que difícilmente uno puede dejar de cargar consigo. El sistema de consigna resulta ser entonces indispensable para los visitantes en general, lo que implica no solo a la familia y a los amigos que ingresan a la cárcel como visitantes, sino también a las personas que ingresan los días que no son de visita, y particularmente los abogados, que se encuentran sometidos a las mismas reglas, 
como lo subraya Emmanuel:

(Mi trabajo) consiste en darle la mano a los abogados, porque no pueden ingresar celulares, chips, cargadores, llaves, correas, etc., y guardamos sus cosas. Van a entrevistarse con sus defendidas, salen, le entregamos sus cosas, sus pertenencias, y ganamos una... una pequeña propina de parte del abogado para... bueno para ayudarnos porque...

El abogado en este caso que te deja llave y celular ¿cuánto le cobras?

Un sol. Un sol por dos, tres horas.

Ya que la tienda de María Teresa abre únicamente los días de visita, Emmanuel goza solo de los ingresos vinculados a la prestación de este servicio, lo que compensa en parte el hecho que tenga una actividad comercial regular mayormente vinculada con los visitantes hombres, es decir un solo día a la semana, a contrario de sus vecinas. Hasta hace algunos años atrás, las autoridades penitenciarias solían guardar las pertenencias de los abogados en la entrada del establecimiento6. Ahora bien, después de varios robos por parte del personal penitenciario, la dirección decidió que este tipo de sistema de consigna gratuita no se efectuaría más, sin proponer ninguna otra alternativa. Por ende, los tenderos representan actores satélites indispensables para el sistema de visita en su sentido amplio, pues sus servicios resultan ser esenciales no solo para los visitantes en su conjunto y diversidad, sino también para el sistema penitenciario cuya infraestructura y organización no permiten el respeto del reglamento en materia de visita.

Los ingresos generados por el servicio de consigna dependen paralelamente de otros servicios basados en las necesidades de las internas y sus familiares, que encuentran en estos locales la oportunidad de remediar una vez más a las restricciones del sistema penitenciario. Cada lunes, entre las dos y las cuatro de la tarde, cualquier persona ajena a la cárcel puede presentarse allí para dejar ropa, libros, termos, sábanas y zapatos, entre otros productos que no ingresan durante los días de visita. Siendo el acceso extremadamente restringido en términos de horarios, y ya que se efectúa durante un día comúnmente laboral, los familiares y amigos de las internas pueden recurrir al servicio de consigna y entrega que ofrece Emmanuel y algunas asistentas del local de María Teresa. Emmanuel cuenta cómo se organiza esta parte de su trabajo:

Y acá te dejan paquetes, por ejemplo el termo, un día normal (de visita) no entra ino?

Claro.

Y cuando la interna ha hecho la solicitud, ¿tú mismo ingresas con las cosas al penal?

(...)

Yo envío una nota y en la nota le digo: «Hola, soy Manuel Concha Tenorio, por favor envíame la copia de la solicitud del termo de un litro o litro y

6 Este sistema estaba vigente en 2007, cuando realicé mi primer trabajo de campo en el establecimiento penitenciario de mujeres de Chorrillos. Ingresando como investigadora, el personal del INPE cuidaba entonces las pertenencias que tenía prohibido llevar conmigo dentro de la cárcel. 
medio por favor para llevártelo». Le mando la nota o «llámame por teléfono», llevo el termo con la copia en el departamento de seguridad, dejo el termo y me voy tranquilo.

¿A quién le dejas la nota?

A la señorita (del INPE) que se le da una propina de un sol para que la nota la entregue personalmente a la interna. A la paquetera, se llama acá.

Y tú ¿cuánto cobras para guardar un paquete así?

Igual. Depende. Si es un termo, se le cobra cinco soles ipor qué? Porque dos soles es para la tienda, un sol es la paquetera, dos soles para la persona que lo lleva porque mayormente yo no voy porque estoy solo en la tienda y lo mando con alguien, y doy su propina, dos soles. Es que hay que hacer su cola y pararse.

Efectivamente, las personas que dejan paquetes los días lunes tienen que someterse al mismo proceso que durante un día de visita, por más que la menor afluencia implique un costo temporal mucho menor. Hay que esperar formando una fila, presentar un documento de identidad y las autoridades aplican un sello en el antebrazo para que la persona pueda ingresar a la cárcel, en una sala ubicada cerca de la entrada, donde se depositan los paquetes que serán luego repartidos a las internas. Se trata de la única forma para que las internas accedan a ciertos productos indispensables como los termos. Ya que el agua caliente está distribuida a las delegadas de piso de cada pabellón una vez al día, en la mañana, el termo se convierte en un objeto imprescindible para la preparación de bebidas calientes, a fortiori en invierno. Ya que las autoridades no proveen este tipo de material, las internas tienen que solicitar formalmente su adquisición y luego encontrar a un intermediario que se lo traiga un día lunes. El sistema de consigna-entrega es también indispensable para adquirir sábanas, frazadas y zapatos. No nos encontramos entonces frente a un recurso extraordinario por medio del cual las internas solicitarían algunos productos que podrían parecer superfluos, sino que se trata verdaderamente de un complejo sistema de intercambio que implica una serie de actores e intereses materiales, personales y económicos, cuya existencia resulta posible por la debilidad del sistema penitenciario.

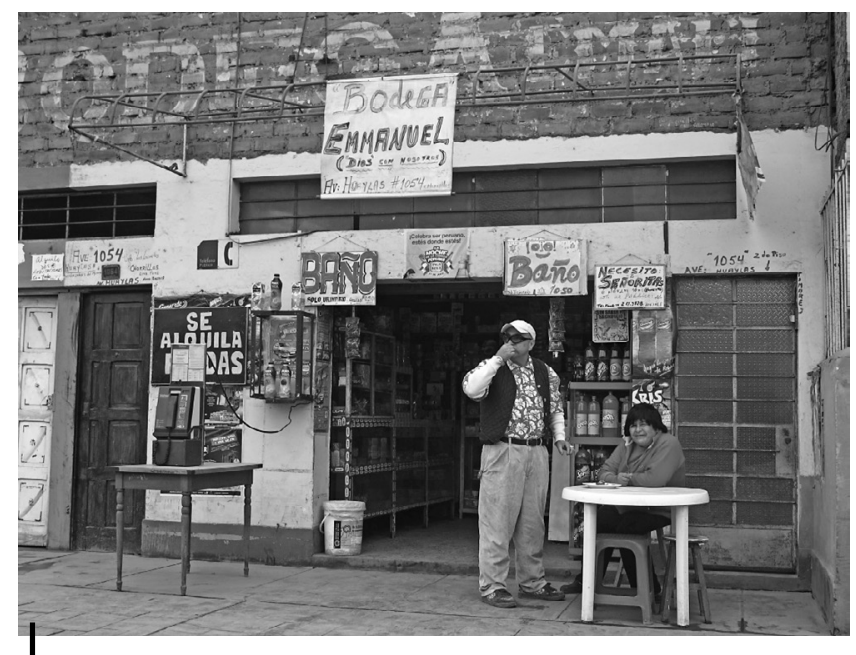

Figura 3 - La actividad comercial de la bodega Emmanuel se encuentra muy restringida fuera de los días de visita

Fuente: archivos personales 


\section{EL NEGOCIO DE PRODUCTOS PROHIBIDOS POR PARTE DE LAS GUARDIAS}

\section{1. Cuando las autoridades hacen carrera en la desviación}

A lo largo de cuarenta años de actividad comercial vinculada al espacio carcelario amplio, el tendero Emmanuel afirma haber sido testigo de numerosos tráficos que implican la participación de las guardias del INPE en ciertas formas de comercio ilegal:

He visto tráfico de licor por ejemplo, las chicas del INPE venían a mi negocio y nadie sabía que yo tengo acá un espejo que yo filmo (en el sentido figurativo) de acá hacia mi baño. Un ojo más, como esta chapa, tú cierras la puerta y de la chapa que tengo filmo todo lo que tengo en mi tienda. $\mathrm{Y}$ he visto gente del INPE así, con su gorra, con su casaca, todo, y viene a comprar, mi madre vendía unas chatas 7 de ron, pisco chiquitos, las mujeres agarraban, se lo ponían en el sostén, cerraban la casaca y vendían adentro. Acá le costaba diez soles y me contaban que adentro lo vendían en cuarenta.

Este tipo de tráfico de parte de los agentes de seguridad incluye una serie de productos cuyo ingreso a la cárcel está formalmente prohibido, pero que las internas suelen usar o consumir. Cubiertos de metal, perfumes, insecticidas o alcohol, estos productos se venden y circulan dentro de la cárcel gracias a la complicidad de las guardias. Estas operaciones ilegales de compra-venta se realizan según dos modalidades distintas. A cambio de unos nuevos soles, las guardias ofrecen recuperar los paquetes que alguna persona externa deposita en la tienda de Emmanuel. Basta entonces con dejar un paquete con el tendero, con una propina de dos a cinco nuevos soles, para que la guardia que se comprometió con una interna lo recoja e ingrese a la cárcel como si fueran artículos personales. Paralelamente, por encargo de las internas, las guardias compran algunos productos como ropa o perfume e ingresan a la cárcel bajo la modalidad descrita anteriormente. Retomando la pregunta que hacía Becker en cuanto a la desviación intencional (Becker et al., 1985: 49), nos podemos preguntar qué motiva a estas figuras de autoridad, a fortiori representantes de una institución que castiga a actores juzgados como desviantes, para cometer este tipo de acto, por medio del cual ingresan a una forma de economía delictiva y transgreden las normas de su institución. Según las observaciones realizadas y los testimonios recopilados durante las visitas y las entrevistas, la regularidad de estas transacciones permitiría a esta funcionarias que perciben un salario muy bajo mejorar sus propias condiciones de vida. Una interna mexicana relata este tipo de prácticas en los siguientes términos:

Las (guardias) tienen sueldo más bajo, se enteran de que (las extranjeras) tienen ayuda de embajada8 y dicen : «¿Cómo puede ser que ellas vivan mejor?» Ellas mismas te venden perfumes, se ganan su plata así.

Botellas chicas.

8 En realidad solamente las internas españolas y holandesas perciben una ayuda económica por parte de su embajada. Sin embargo, tanto las autoridades como las demás internas piensan comúnmente que las extranjeras gozan de mayor poder económico que las demás. 
En 2007, para turnos de trabajo de veinticuatro horas, y ejerciendo una labor riesgosa, los guardias del INPE percibían un salario de 700 nuevos soles, es decir apenas más que el salario mínimo entonces vigente. En 2012, este salario había subido a 1200 nuevos soles, pero los empleados del INPE estimaban que seguía insuficiente para cubrir sus necesidades básicas, considerando los riesgos a los que se encontraban expuestos (2012). Finalmente la regularidad de estas prácticas permite afirmar que nos encontramos frente a «un grupo desviante organizado» que racionaliza su posición — vía la cuestión salarial— y que aprendió a «llevar a cabo las actividades desviantes con un mínimo de problemas» (Becker et al., 1985: 60-61). Sin embargo, ya que ninguna entrevista se ha realizado con las guardias, no me es posible confirmar la tercera característica del grupo desviante que destaca Becker, que concierne la «recusación global de las normas morales convencionales, de las instituciones oficiales y más generalmente de las convenciones ordinarias» (Becker et al., 1985: 62).

Las internas que recurren a este tipo de servicio, muy frecuentes según los testimonios que pude recoger durante los días de visita, invitan regularmente a las guardias que se prestan a este juego a compartir alguna bebida o galleta. Según cuenta Janeth, una joven interna entrevistada en 2011, las relaciones entre internas y guardias están regidas por un principio de dominación, en la medida en que las primeras dependen de las segundas para adquirir ciertos productos:

Aquí si quieres ser amiga de las INPEs tienes que darles. Si no le das te miran como una rata. Yo le pedía unas sandalias de afuera que acá no pueden entrar. Le das 10 soles y ella te lo trae, le das 15 soles y te trae radio. Y te piden comida. Siempre te piden cosas.

Finalmente las internas como Janeth deben tratar con las guardias en un juego de frágil equilibrio ya que el poder permanece en manos de la autoridad. Consecuentemente, tienen que someterse a las exigencias de las guardias para poder gozar de esta forma de comercio. Por más abajo que se encuentre la figura de la guardia en la escala jerárquica administrativa, constituye la representación del poder más cercana a las internas. Por ende, si las internas que solicitan a las guardias este tipo de servicio quieren seguir gozando del privilegio de poder usar o consumir algunos productos, no pueden contravenir a las formas de pago adicionales que solicitan las mismas autoridades.

\section{2. Venta, confiscación y reventa: un círculo comercial ilícito dominado por el poder oficial}

Por medio del comercio ilícito, la figura de la autoridad que representan las guardias penetra la esfera de un doble juego. Por un lado, ellas son las que facilitan el ingreso de algunos productos prohibidos, y por otro también son ellas quienes cumplen las órdenes de inspección y requisas de las celdas, decididas por la dirección del establecimiento. Encontrar objetos prohibidos aparece entonces de lo más fácil si se considera que las guardias saben — por lo menos en partequiénes son las internas que los poseen. Durante conversaciones informales que he tenido con varias internas, muchas de ellas tuvieron la oportunidad de quejarse 
de las requisas que habían sido realizadas poco antes de nuestros encuentros. Su discurso traduce un sentimiento de profunda injusticia y engaño: «(Las guardias) mismas te venden las cosas, te las quitan iy luego te la venden de vuelta!», me contó una de ellas. Su sentimiento de injusticia crece cuando después de confiscárselo, las guardias les ofrecen volver a comprar un producto que ellas mismas les había vendido anteriormente. Roxana cuenta así:

Acá hay bastante abuso de las (guardias), yo no me dejo. También con las extranjeras, les venden cosas demasiado caras, luego les quitan todo.

Según lo que pude escuchar durante los días de visita, estas prácticas son muy frecuentes y conciernen a numerosas guardias e internas. Los empleados del INPE que se dedican a ellas multiplican entonces los ingresos por medio de un ciclo donde intervienen por turno su papel oficial y oficioso, y su comercio resulta ser aún más lucrativo pues ciertos productos se mantienen en el círculo de ventaconfiscación-reventa durante cierto tiempo.

La requisa constituye obviamente un motivo de tensión para las mujeres que poseen objetos prohibidos. Elena cuenta que tiene un lector de música mp3, pero teme las consecuencias:

Sí, tengo mp3. Que no me pillen las (guardias) porque me lo quitan, pero tengo mp3.

A pesar de su presencia numeraria relativamente débil9 y un poder coercitivo y punitivo desacreditado por la corrupción y los distintos tipos de tráfico, los miembros del equipo de seguridad del INPE constituyen finalmente figuras que las internas temen más de lo que respetan. Elena es consciente que la reiteración de la confiscación le puede valer una pena de calabozo. En realidad, estas penas están generalmente aplicadas a las internas en cuyas celdas se encuentra droga. Más allá del castigo de calabozo, estas internas también se exponen a ser transferidas a una cárcel de máxima seguridad o a un establecimiento de provincia. Las estrategias empleadas por las internas para conseguir droga y protegerse de las sanciones administrativas, así como el papel que pueden desempeñar algunos empleados del INPE en esta forma de economía delictiva, podrán ser objeto de un análisis profundo en otra oportunidad.

\section{CONCLUSIÓN}

El sistema económico que se tejió a lo largo del tiempo entre el adentro y las afueras del establecimiento penitenciario de mujeres de Chorrillos incluye a una diversidad de actores y operaciones que fueron presentados y analizados aquí. Por un lado, la existencia y el desarrollo de este sistema responde a la debilidad y falta de adaptación de la administración penitenciaria frente a una población cambiante y en permanente crecimiento numerario. Por otro lado,

9 En 2007, pude observar que el equipo de seguridad del establecimiento de mujeres de Chorrillos estaba conformado por 25 guardias que tenían que asegurar la custodia de más de 1200 internas. 
el funcionamiento paralelo de las economías formales, informales e ilícitas, que se desarrollan en un espacio amplio, responde a una cultura de transgresión e informalidad que el Estado no supo contrarrestar conforme aparecieron nuevas necesidades de todas las partes. En efecto, ampliando la mirada, la variedad de productos ofrecidos, pedidos y vendidos, también puede ser considerada como el resultado de transformaciones neoliberales que sostienen patrones de consumo que desean seguir hasta las personas privadas de libertad más pobres. Seguir estos modelos permite a las internas no cortar totalmente con las realidades exteriores e intentar mantener cierto estándar de vida, lo que les evita un corte abrupto con los modos de vida que experimentaban antes del encarcelamiento. Pero existe también una verdadera diferencia que divide a las internas en función de los ritmos de consumo que tienen dentro de la cárcel, pues el sistema económico que los rige puede acentuar diferencias socioeconómicas que preexistían al encierro y que se encuentran reforzadas por el modelo penitenciario tal como funciona en la actualidad. La porosidad de las paredes de la cárcel en términos de relaciones humanas y de acceso a los medios de comunicación permite y refuerza la emergencia de ciertos deseos y exigencias, asegura la supervivencia de un gran número de personas vinculadas a este universo, y reafirma la inscripción del espacio carcelario dentro de una sociedad determinada.

\section{Referencias citadas}

2012 - Trabajadores del INPE en huelga: «Nuestra situación es insostenible». El Comercio, 25 de enero.

BECKER, H. S., CHAPOULIE, J. M. \& BRIAND, J.-P., 1985 - Outsiders : Études de sociologie de la déviance, 248 pp.; París: A.-M. Métailié.

BETALLELUZ, B., 2006 - Los informales en la economía, un antiguo problema. La PEA arequipeña en1847. In: Pueblos, provincias y regiones en la historia del Perú: 497504; Lima: Academia nacional de la historia.

BIELICH SALAZAR, C., 2009 - La Guerra del centavo. Una mirada actual al transporte público en Lima Metropolitana, 124 pp.; Lima: Instituto de Estudios Peruanos.

CANAZA PAREDES, S., 2006 - El contrabando de cds iformal o informal en Oruro? In: XX Reunión anual de etnología. Itinerancias identitarias: permanencias y cambios sociales: 419-426; La Paz: Museo nacional de etnografía y folklore (MUSEF).

CONSTANT, C., 2011- Solidarité et inégalités. Le centre de détention de femmes Santa Mónica à Lima, 162 pp.; París: IHEAL, coll. Chrysalides, no 10.

CONSTANT, C., 2013 - Trajectoires et dynamiques carcérales au féminin. Le cas de Lima; París: Université Paris III-Sorbonne Nouvelle, Institut des Hautes Études de I'Amérique Latine. Tesis de doctorado.

CROZIER, M. \& FRIEDBERG, E., 1996 - L'acteur et le système : les contraintes de l'action collective, 248 pp.; París: Seuil. 
CUNHA, M. D., 2005 - From Neighborhood to Prison. Women and the War on Drugs in Portugal. In: Global Lockdown. Race, Gender, and Prison-Industrial Complex (J. Sudbury, ed.): 155-165; Nueva York: Routledge.

DASTON, L., 1995 - The moral economy of science. Osiris, 10: 2-24.

DURAND, F., 2007 - El Perú fracturado: formalidad, informalidad y economía delictiva, 284 pp.; Lima: Fondo Editorial del Congreso del Perú.

FASSIN, D., 2009 - Les économies morales revisitées. Annales HSS, 6: 1237-1266.

GONZÁLES, J., 2001 - Redes de la informalidad en Gamarra, 244 pp.; Lima: Universidad Ricardo Palma.

GROMPONE, R., 2005 - El sector informal y su relación con el estado. In: ¿Hay lugar para los pobres en el Perú?: las relaciones estado-sociedad y el rol de la cooperación internacional (P. Zárate, ed.): 133-201; Lima: Ministerio británico para el desarrollo internacional.

HÉRITIER, F., 1996 - Masculin, Féminin. La pensée de la différence, 322 pp.; París: Odile Jacob.

INSTITUTO NACIONAL PENITENCIARIO, 2012 - Informe estadístico. Diciembre 2012, 87 pp.; Lima: Instituto Nacional Penitenciario. http://www.inpe.gob.pe/pdf/ diciembre2012-e.pdf

SOTO, H. D., 1986 - El otro sendero: la revolución informal, 317 pp.; Lima: Editorial El Barranco. 